\title{
Dramaturgy of Robots and Machines
}

\author{
Carla Capeto \\ Independent \\ 43 Ollerton Green, E3 2LB London, UK \\ carlacapeto@gmail.com
}

\begin{abstract}
It is undeniable that digital technologies transformed contemporary artistic practice and cultural production. Particularly in the field of the performing arts, technology changed the relationship with the public narrative processes, creating an avenue to investigate contemporary dramaturgical practices. This paper investigates the dramaturgical transformations as a result of the increasing use of robotics in performance with the support of theories of Marianne Van Kerkhoven (2009a; 2009b) Katalin Trencsényi, Bernadette Cochrane (Trencsényi \& Cochrane 2014) and Peter Eckersall (Eckersall et all 2017). Based on this theoretical framework, this paper looks into themes and narrative strategies that explore the relationship and emotional connection between humans and robots. This is done through the analysis of the Hirata Oriza, Mari Velonaki, Blanca Li or Max Dean. To further the study of a dramaturgy of robots and machines, this paper analyses the concept systematurgy (Antúnez 2016), a methodology that provides an insight into Marcel-Lí Antúnez's body of work. Systematurgy demonstrates how Antúnez articulates technology and machine-like elements within a dramaturgical process. Unlike traditional theatre, Antúnez's dramaturgical model is not focused on the textual elements but integrates coding, image, drawing, robotic and mechanical elements into the narrative structures of performance.
\end{abstract}

Dramaturgy. Robots. Performance. Theatre. Installation.

\section{HISTORICAL BACKGROUND}

The word robot appears for the first time in 1920 on Karel Čapek play R.U.R (Rossum's Universal Robots) (Čapek \& Novack 2004). In the context of the play, the word robot does not describe a mechanical creature but rather an artificial and synthetic human conceived for factory labour.

R.U.R is a critical reflection of a cultural shift rooted in the 19th century technological and scientific innovations. The play takes on the idea of a body trapped in the dynamics of an industrialised economy and society. The idea of the robot conveys a negative view of the impact of industrial and technological development, which enslaves the body and changes the human condition. Technological determinism addresses this idea upholding the view that technology is the driving force of human history and culture: "Machines make history by changing the material conditions of human existence" (Heilbroner 1994, p.69). Although technological determinism does shed a light on the effects of the technology impact in our life and culture, the relationship between technology and culture is a result an interaction between different factors. Meyerhold's work is an example of that interaction. Amid the Soviet revolution, Meyerhold created a new acting system, the biomechanics, inspired on theories of industrial mass production of Taylorism and Fordism (Pitches 2003), Russian Futurism and Constructivism. He merged the human body with the industrial machine to create a new aesthetic language. Similarly, Oskar Schlemmer, while in charge of the Bauhaus Theatre, also explored the bodily perception of space through the composition of body movements that were inspired by mechanical technology and the mechanics of puppetry (Trimingham 2011, p.332).

The aesthetics of the machine continued to echo in artistic exploration in the 1960s. Jean Tinguely's Homage to New York performed its self-destruction in front of an audience. The sculpture offered a truly interactive experience with movement, sound and visual that ultimately would perform its own death (Dixon 2007, pp.284-285). Another innovating work is Nam June Paik's Robot K-456 anthropomorphic robot developed in collaboration 
with Shuya Abe in 1964 that performed while walking the streets. Nonetheless, the pivotal moment in the history of robotics and engineering in the arts was 1968's Cybernetic Serendipity commissioned by Jasia Reichard. The exhibition launched a debate on the disciplinary crossover between computer science, cybernetics, and art. Moreover, it celebrated the social and cultural shift that was already in course at the time. According to Steve Dixon, Cybernetic serendipity was a prediction of the computer as a social and cultural phenomenon:

\begin{abstract}
The computer's role as an accessible art for all machine would be confirmed later, when Apple released its very first home computer in 1984, which was sold with integral painting and drawing programs (2007, p.102).
\end{abstract}

Edward Inhatowicz and Gordon Pask were among the 130 artists commissioned for the Cybernetic serendipity exhibition. Edward Inhatowicz exhibited SAM (Sound Activated Mobile), a robotic sculptures that responded to the sound of the audience. The interaction between the audience and SAM created a unique experience where each member of the audience became a performer. The whole experience could even be considered a reciprocal performance. As the audience performed, the robotic sculpture, in return, performed to them.

Gordon Pask exhibited the robotic installation Colloquy of Mobiles, a computer-based assembly of five autonomous and independent mobiles that interacted with each other and established a cybernetic conversation. Another contribution that is not frequently mentioned is Pask's Proposals for a Cybernetic Theatre (1964), which he wrote whilst collaborating with Joan Littlewood and Cedric Price in the project Fun Palace. Although his proposal does not specifically address robotic machines, is an early example of a dramaturgical proposal that integrates technological systems into a dramatic structure.

Towards the latest decades of the 20th century and the beginnings of the 21st century, the presence of robots in arts (and specifically in the performing arts) intensified and diversified. There is more emphasis on the autonomy of robots and their social interaction with humans. For example, Simon Penny's non-anthropomorphic robot, Petit Mal, intelligently interacts with its environment and people. However, the human-robot relationship began to adopt other forms of expressions and robotics becomes an extension of the human body. Stelarc and Marcel-lí Antúnez explored the posthuman relationship of technology with robotic extension of the body. This is noticeable in Stelarc's The Third Hand and Marcel-lí Antúnez's Dreskeleton performances where the juxtaposition of body and technology remits to body enhancement and control.

For over a century, artists explored robotics machines technically and conceptually. They reflected on the socialcultural impact of technology and the human condition regarding its relationship with robots. This brief historical introduction aims to open an avenue to discuss the use of robotic technology in performance and to analysis common trends in the narratives of robots.

\section{SHIFT OF DRAMATUGICAL PARADIGMS}

The introduction of robotic technology in the performing arts is the result of breaking boundaries between disciplinary field. Science, engineering and the arts came together, in some cases, as a celebration of society advancements or as critical gaze. Looking back at the earliest examples, we can identify different stances regarding technology and the mechanical body in Čapek's R.U.R and Meyerhold. Čapek provides a pessimistic view on the impact of modern technology whilst Meyerhold celebrates it.

Robots, exoskeletons and interactive machines have profoundly impacted the performing arts on many levels. They introduced new concepts and themes, changed narrative structures, scenography, staging and reconfigured the relationship between the performance and the public. Finding balance and coherence of all these elements is a dramaturgical concern, as Adrian Heathfield describes it:

(...) dramaturgy is frequently charged with the tasks of the guardianship and restoration of event-structure (2011, p.106).

Heathfield also stresses that dramaturgy is not exclusive to theatre and can expand to other fields where performance is also taking place (2011, p.115). Lehmann and Primavesi (2009) corroborate this viewpoint and highlight the role of new media technologies for the transformation of dramaturgical practice.

To better understand the dramaturgical implications of the use of robots in performance, we need to look into the ongoing research on new dramaturgies. Dramaturg Marianne Van Kerkhoven publishes an article on Theatershift, On Dramaturgy (2009b), where she reflects about the conversation that took place at the symposium Context 01: Active Pooling, the New Theatre's Word Perfect in Amsterdam. She noted that there was an overall sentiment that dramaturgy was going through a paradigm shift. However, no one could pinpoint what that shift was. Thus, Kerkhoven created the term new dramaturgy as a way of 
distinguishing it from the traditional forms. New dramaturgies are concerned with solving the chaos of creative processes and producing a heterogeneous amalgamation of the performance elements (2009b, p.18).

In the paper European dramaturgy in the $21^{\text {st }}$ century (2009a), Kerkhoven expands her ideas to a broader context, analysing how political and economic pressures have affected the artistic production. As cultural production moves faster and boundaries between disciplines are blurred, dramaturgy needs to adapt and find new grounds to strive.

The term new dramaturgies still echoes in current research. Katalin Trencsényi and Bernadette Cochrane (2014) describe new dramaturgies as a dynamic field made of a "multitude of theories and aesthetics, and the diversity of practices" (p.xii). They recognise three main characteristics: postmimetic, intercultural and process-conscious. The post-mimetic refers to the decline of the representational and mimetic of Aristotelian tradition of theatre. Intercultural is the embracing of the multiplicity of cultural values, which according to the authors also involves the intersection of different disciplines. Hence, interculturalism also involves interdisciplinarity. Finally, processconscious, in which dramaturgy becomes concerned with the evolution stages and with elements of the performance production. These three characteristics are currently found in several dramaturgical explorations, in which is included Peter Eckersall's New Media Dramaturgy and his approach on a dramaturgy of robots (Eckersall et al. 2017).

Peter Eckersall advances a theory of new media dramaturgy, or NMD, that merges the ideas of new dramaturgies with media performance. The letter ' $M$ ' in the acronym NMD stands for media and for the "materiality of objects and the fact that they are now beyond metaphor, giving rise to a complex political economy of simulation" (Eckersall et al. 2017 , p.125). Eckersall sees robots as objectfigures that possess a performative expressivity capable of projecting an emotional dimension on the public. Therefore, robots are not ornaments for a performance, but dramaturgical signifiers.

\section{NARRATIVES: ROBOTS, FRIENDS OR FOES?}

Boston Dynamics is one of the companies at the forefront of science and engineering research in robotics. They released several documenting videos on social media that show tests of robots's performing several tasks such as walking or opening doors (2010). We frequently see the company's engineers being quite ruthless and aggressive with their robots. The YouTube comment section of these videos shows the reaction of people who often disapprove the behaviour towards the robots. Even though we rationally know those robots are not feeling any pain, we still perceive Boston Dynamics staff's behaviour as aggressive and inappropriate.

Empathy, fear or eeriness are frequent emotional reactions to robots or robotic objects. The death of NASA's Opportunity rover on Mars after a dust storm generated a wave of sobbing compassion from people on Earth, which is something that Hiroshi Ishiguro's robots would hardly achieve. The human likeness of his robots might not play well when it comes to conquering human empathy. Masahiro Mori tackles this phenomenon in the theory of the Uncanny Valley (2012), describing how people relate to robots based on their likeness to humans. When robots have a high level of human resemblance, it generates feelings of aversion.

Our emotional connection with robots serves a dramaturgical purpose for the performing arts. They underlie the narratives of servitude and companionship, portraying the robot either as a friend or a foe.

These narratives reflect real-world concerns such as the robotisation of labour, which is a theme present in Blanca Li's Robots. Although the performance is not as pessimistic and dystopian as Karel Čapek's R.U.R, it raises questions about the role of human and robots in modern society. Robots have also generated contrasting narratives that, to some extent, are due to cultural differences. Steve Dixon (2007, p.285) notes that the perception of robots differs from West to East. Japan, for instance, has a more optimistic and enthusiastic approach but artists still critically addresses concerns regarding the human-robot relationship.

In Sayonara and I, Worker, Hirata Oriza explores existential questions about the human condition: the meaning of life, death and human emotions. In both plays, empathy in robots is part of the narrative. In a scene of $I$, Worker, while the female actor and robot engaged in a conversation during a meal, the robot apologises for speaking of children, recognising that is a sensitive topic for the human. However, the robot fails to understand the complexity of the issue, showing that there is a contrast between human and robot sensitivity.

Hirata chose commercial robots for both plays. In Sayonara one of Ishiguro's female actroids played the human companion of a dying woman, and for ' $l$, Worker' Hirata used Mitsubishi Wakamaru robot to play a domestic assistant. Based on the views of Jennifer Robertson's Robo Sapien Japanicus 
(2018), Eckersall recognises a contrast between the themes of the play and the commercial purpose of those robots. He argues that roboticists have no interest in the social or political value of robots (2017, p.118).

British company Engineering Arts also develops commercial robot actors such as the Robot Thespian available for rental. It is hard to predict how much these practices will increase in the future but if they do they could have significant dramaturgical implications. This could lead to a standardisation of robot performers and limit the artistic exploration of robots in performance as well as reducing the possibilities for closer collaboration between artists, scientist and engineers. Moreover, it requires substantial production and budgetary resources. Robots like Ishiguro actroids or the Robot Thespian are a luxury that many theatre or dance companies cannot afford, which would create differences in the approach of robots in performance.

The robotic installation Fish and Bird by Mari Velonaki also alludes to a certain humanisation of robots through empathy. The robots are two wheelchairs that poetically transmit the feelings of absence and loneliness. The emotional connection does not lie on human-likeness but on the context of the situation of the two wheelchairs. The installation aims to generate empathy on the audience. Eckersall describes phenomena like this as an emergence of new modes of subjectivity, as something that goes beyond the mere human projection onto inanimated things (2015). However, the projection of human emotions and affections is crucial to understand robots as performers and their relationship with the public and the human performers. We could even call them robots of the affect.

The concept of empathy is an interesting idea to explore in a dramaturgy of robots. Firstly, it provides a thematic platform to address social, economic and political topics regarding the impact of robots on our society. Secondly, empathy can be used as a strategy of emotional engagement for the audiences.

The strategies of engagement can be as simple as creating a context, staging the robots in particular situation, or choreographing the robots movements in a way that will trigger familiarity. It is not necessary to have a human-like robot to establish an emotional connection with the audience. There is always an association with a human behaviour, which can lead to meaningful narratives and poetic readings. Max Dean's self-assembling Robotic Chair and RobotLab's Bios are examples of nonanthropomorphic robots that can generate that human connection. Max Dean's chair self-destructs to then get back together whilst RobotLab's Bios writes the bible in old calligraphy in a seemingly human pace. Both artworks evoke human-like qualities that endow the robots with a poetic meaning.

\section{SYSTEMATURGY, A BRIEF CASE STUDY}

Peter Eckersall, Helena Grehan and Edward Sheer (2017) made a valuable contribution in bringing closer the theories of new dramaturgy and robots. However, they set little focus on artistic processes.

Spanish artist and performer Marcel-Lí Antúnez developed a methodology he calls systematurgy, which compiles the principles of his mechatronic performances. He published a book also called Sytematurgy (2016) that provides an insight into his body of work and his pursuit of the integration of the logic of computational systems in the narrative structure of his mechatronic performances.

\begin{abstract}
Systematurgy is the methodology I use in the production of actions and installations, based on computational management, which affects both creation and the presentation of works. It provides new materials, new ways of writing, new devices and new ways of imagining interactivity (2016, p.119).
\end{abstract}

Robotic elements have a strong presence in Marcel-Lí Antúnez and are combined with other elements such as drawing, video and real-time performance. Epizoo is a performance where Marcel-Lí Antúnez is connected to a Dreskeleton, a robotic exoskeleton that allows the public to control the artist's body. He juxtaposes the human body and robotic elements creating a relationship that is, somehow, aggressive, of dominance and dystopian with elements visceral hybridity. Joan, l'home de carne is an organic robot made of real meat remitting to Marcel-Lí Antúnez family origins and his father's job as a butcher. This grotesque robot was placed inside of a box and responded to the sounds made by the audience. In his book, MarcelLí Antúnez reflects on the dramaturgical process and principles of each performance, but there are some transversal ideas in his body of work. Antúnez advocates hybridity and symbiosis of elements and disciplines, emphasizing sociocultural heritage and newness of the technology.

In his book, Marcel-Lí Antúnez reflects on the dramaturgical process and principles of each performance but there are some transversal ideas in his body of work. Antúnez advocates hybridity and symbiosis of elements and disciplines, emphasising sociocultural heritage, the newness of and materiality of technology. The materiality of technology is also a characteristic that Peter 
Eckersall includes in his theory of new media dramaturgy. He also reflects on the interactions as a new type of relationship that surpassed the initial artistic intentions (2016, p.16). For example, in Joan, L'home de Carne, the public's reactions went from dogs barking and people signing or shouting at the robot expression aversion for it.

Systematurgy proposes a new dramaturgical model that aligns with the theories proposed by Trencsényi and Cochrane (2014). It is postmimetic, interdisciplinary and process-conscious. Systematurgy is a postmimetic model because it does not rely on literary or dramatic text and all elements play a role in the composition of the performance, in which drawing is sometimes the main dramaturgical tool. Drawing provides MarcelLí Antúnez's work with a very distinct aesthetics and becomes a means of escaping the traditional text-based theatre format. It is interdisciplinary because it integrates different types of technologies and mediums. Finally, systematurgy is processconscious because it is an inclusive methodology that integrates all aspects of production: analyses institutional and collaborative relationships, and articulates every performance element, in particular the technological element.

\section{CONCLUSION}

This paper explored two strands of dramaturgy of robots: narratives, looking at themes of empathy and emotional connection; and process through a brief analysis of Marcel-li Antúnez's work methodology, systematurgy. Although this paper is just scratching the surface of a field, it has identified open possibilities for further investigation.

Firstly, by adding a dramaturgical perspective, we can strengthen the debate around the cultural and social relevance of robots within the artistic community. Secondly, it would also allow the sharing of ideas and methods to reinforce collaboration across different disciplines and develop a deeper understanding of the perceptual relationship of the audience regarding robots. Thirdly, a dramaturgical analysis of the processes and narratives helps us to think about what kind of performer a robot is, as robots are not comparable to human actors. Robots do not have the same expressivity as humans. Finally, robots are changing artistic processes. Allowing a dramaturgical practice would provide an insight into new paradigms of artistic creation, what characterises them, and how they relate to each other.

\section{REFERENCES}

Antúnez, M. R. (2016) Sistematurgy. Polígrafa, Barcelona.

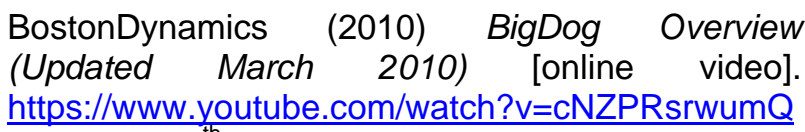
(retrieved $15^{\text {th }}$ March 2020).

Čapek, K. \& Novack, C. (2004) R.U.R. (Rossum's universal robots). Penguin Books, London.

Dixon, S. (2007) Digital performance. MIT Press, Cambridge, MA.

Eckersall, P. (2015) Towards a Dramaturgy of Robots and Object-Figures. TDR/The Drama Review, 59 (3), pp.123-131.

Eckersall, P., Grehan, H. \& Scheer, E. (2017). New Media Dramaturgy. Palgrave MacMillan, New York.

Heathield, A. (2011) Dramaturgy without a dramaturge. In Bellisco, M., Cifuentes, M.J. \& Ecija, A. (eds). Repensar la dramaturgia: errancia y transformación Seminario. Centro Párraga/CENCDOC, Murcia.

Heilbroner, R. L. (1994) Technological determinism revisited. In Marx, L. (ed.) Does technology drive history? The dilemma of technological determinism. MIT Press, Cambridge, MA.

Lehmann, H-T. and Primavesi, P. (2009) 'Dramaturgy on Shifting Grounds'. Performance Research, 14(3), pp.3-6.

Masahiro, M. (2012) The Uncanny Valley. https://ieeexplore.ieee.org/stamp/stamp.jsp?tp=\&ar number $=6213238$ (retriecved 16 March 2020)

Pask, G. (1964) Proposals for a Cybernetic Theatre.

http://www.pangaro.com/pask/ProposalCyberneticT heatrePask1964r.pdf (retrieved 30 July 2015).

Pitches, J. (2003) Vsevolod Meyerhold. London: Routledge.

Robertson, J. (2018) Robo sapiens japanicus. University of California Press, Oakland, CA.

Trencsényi, K., Cochrane, B. (2014) New dramaturgy: international perspectives on theory and practice. Bloomsbury Publishing, London.

Trimingham, M. (2011) The theatre of the Bauhaus. Routledge, New York.

Van Kerkhoven, M. (2009a) European Dramaturgy in the $21^{\text {st }}$ Century. Performance Research, 14(3), pp.7-11.

Van Kerkhoven, M (2009b) Performance Research. On Dramaturgy: Notes on Contributors. Performance Research, 14(3), pp.132-134. 